\title{
A Messianic Theory of Digital Knowledge: On Positivism and Visualizing Rosenzweig's Archive
}

\author{
Does not positivism 'reflect' a reality in which \\ man has surrendered to the authority of facts, in \\ which reason, autonomous and critical \\ thinking, is actually subordinate to observation \\ of facts? Does the term 'positive' in positivism \\ not really imply a positive, that is to say, \\ affirmative attitude towards the matters of fact- \\ whatever they might be? \\ Herbert Marcuse (1941)
}

Since the 1930s and 1940s, the accusation of positivism has been one of the most severe criticisms in the humanities, as Marcuse's rhetorical questions suggest. ${ }^{1}$ For the first generation of critical theorists, the word "positivism" signified the dangerous acceptance and replication of the status quo and, in 1941, the political acquiescence to Nazi totalitarianism as it spread across Europe. In Max Horkheimer and Theodor W. Adorno 's Dialectic of Enlightenment (1947), the "scientific philosophy" of the logical positivists, a rival school of young philosophers in Vienna, had assumed "the judicial office of enlightened reason" as it returned to the myth and barbarism that was the middle of the past century. ${ }^{2}$ Even after the war, positivism remained persona non grata in critical theory, as second generation members of the Frankfurt School, such as Jürgen Habermas, adapted and perpetuated the criticisms of the first. ${ }^{3}$ With the popularization of big data and

1 Quotation from Marcuse's review of John Dewey's Theory of Valuation, which appeared in 1939 in the International Encyclopedia of Unified Science, a book series organized by the Vienna Circle; Herbert Marcuse, "Review of John Dewey's Theory of Valuation," Zeitschrift für Sozialforschung 9, no. 1 (1941): 145.

2 Max Horkheimer and Theodor W. Adorno, Dialectic of Enlightenment, ed. Gunzelin Schmid Noerr, trans. Edmund Jephcott (Stanford: Stanford University Press, 2002), 19. See also Jürgen Habermas, Theory of Communicative Action, trans. Thomas McCarthy, vol. 1 (Boston: Beacon Press, 1984), 22-24.

3 The dispute between the Frankfurt School and the Vienna Circle before the war set the stage for the so-called "positivism dispute" (Positivismusstreit) of the 1960s, between the critical theorists and the critical rationalists, Hans Albert and Karl Popper. For a thorough investigation, see Hans-Joachim Dahms, Positivismusstreit: Die Auseinandersetzungen der Frankfurter Schule mit

๑ OpenAccess. () 2021 Matthew Handelman, published by De Gruyter. (cc))BY-NC-ND This work is licensed under the Creative Commons Attribution-NonCommercial-NoDerivatives 4.0 International License. https://doi.org/10.1515/9783110536539-004 
the digital humanities, positivism has reentered the humanistic milieu as an intellectual slight. ${ }^{4}$ And yet critical theory's decades-old antagonism toward scientific rationality (as salient as it may be) has left us with few conceptual tools to approach the digital in the humanities, save to denounce, as Ted Underwood writes, any quantitative, computational, or empirical humanistic work as "positivist."5 Positivism's return makes one wonder how (or, perhaps, even if) students and scholars, librarians and archivists can employ digital techniques while not only striving for the critical goals, but also practicing the critical methodologies of the humanities.

One answer to this questions lies, as is the contention of this article, in Jewish intellectual life in the German-speaking world during the early twentieth century, which helped give positivism and critical theory the forms in which we recognize them today. ${ }^{6}$ The following analysis argues that one of the forerunners of the critical theorists-the German Jewish philosopher, theologian, and translator Franz Rosenzweig-offers inroads for imagining alternative, critical epistemologies in the digital humanities, such as data visualization. Expanding my previous work in visualizing the metadata of Rosenzweig's diasporic archive, I maintain that Rosenzweig's "messianic theory of knowledge" and its idea of "verification" (which I refer to in the German "Bewährung") helps us come to terms with the dual empirical and metaphysical nature of the digital in the humanities. ${ }^{7}$ For Rosenzweig, it was the iterative, worldly actions of individuals and groups that, in the course of historical time, "verified" forms of knowledge such

\footnotetext{
dem logischen Positivismus, dem amerikanischen Pragmatismus und dem kritischen Rationalismus (Frankfurt am Main: Suhrkamp Verlag, 1994).

4 See, for instance, Andrew Goldstone, “'Positivist' and Other Terms of Praise,” Blog, ARCADE, August 9, 2013, https://arcade.stanford.edu/blogs/positivist-and-other-terms-praise.

5 Underwood tweets: “Dear friends who call all forms of empirical inquiry 'positivism': I have given up trying to nuance your account of history and will instead advance mutual understanding by calling everything you do 'German idealism.”' (@Ted_Underwood), “Dear friends....” Twitter, July 9, 2018, https://twitter.com/ted_underwood/status/1016299439257018369.

6 On the "Jewishness" of the Frankfurt School and the Vienna Circle, see: Jack Jacobs, The Frankfurt School, Jewish Lives, and Antisemitism (Cambridge: Cambridge University Press, 2015), chap. 1; Lisa Silverman, Becoming Austrians: Jews and Culture between the World Wars (Cambridge: Oxford University Press, 2012), 60-65.

7 This previous work explores the decisions required in extracting and visualizing the metadata contained in the finding aid for Rosenzweig's papers at the University of Kassel. These decisions can be understood as translations and theorized with the help of Rosenzweig's own work on the topic; conversely, the visualizations also reveal larger conversations over Rosenzweig's theory of translation and its relevance for the digital age. Matthew Handelman, "Digital Humanities as Translation: Visualizing Franz Rosenzweig’s Archive” 10, no. 1, accessed December 26, 2015, http://transit.berkeley.edu/2015/handelman/.
} 
as religious belief, for which an ultimate, messianic "proof" lay outside of time. My thesis is not that the digital humanities do "Bewährung." Rather, it is that the concept of "Bewährung" mediates between the Absolute and the particular, between the ideal and the real, and, finally, between different modes of knowledge -scientific, philosophical, and religious-in ways that provide an epistemological strategy such that digital humanists might avoid the bland positivism often associated today with the digital.

But what do we mean when we say the word "positivism" and what exactly does it mean to call a digital humanist a "positivist"? Given its modern formulation by Auguste Comte in the nineteenth century, positivism holds that true, "positive" knowledge comes solely from empirical phenomena that are verifiable through sensory experience. ${ }^{8}$ The positivist framework continued in the early twentieth century through thinkers like Ernst Mach and the aforementioned Vienna Circle, whose platform of logical positivism held that "there is knowledge only from experience, which rests on what is immediately given" and through the method of "logical analysis."9 In both positivisms, "positive," verifiable knowledge contrasts what we could call "negative" knowledge in theology and metaphysics, which lacks empirical verification and which the logical positivists rejected as the stuff of "not theory or communication of knowledge [Wissen]," but rather "poetry or myth." humanities a number of laudable scholarly inclinations, such as a dedication to collaborative, cross-disciplinary research. ${ }^{11}$ And yet, like the term neoliberalism, positivism has become a catch-all criticism signifying the so-called political "dark side" of digital work, which, according to its critics, eschews critical and historical thought, is subservient to industry, and promotes neoliberalism it-

8 On the legacy and reach of Comte and positivism, see Michael Singer, The Legacy of Positivism (New York: Palgrave Macmillian, 2005).

9 Anon., "Wissenschaftliche Weltauffassung. Der Wiener Kreis," in Otto Neurath, Empiricism and Sociology, ed. Robert S. Cohen and Marie Neurath (Dordrecht: Reidel, 1973), 309. For more on the history and philosophy of logical positivism, see A. J. Ayer, "Editor's Introduction," in Logical Positivism (New York: The Free Press, 1966), 3-28; Michael Friedman, Reconsidering Logical Positivism (Cambridge: Cambridge University Press, 1999).

10 Anon., "Wissenschaftliche Weltauffassung," 307.

11 The Vienna Circle emphasized the collaborative nature of their work and its interest in the foundations of subjects from arithmetic to the social sciences; Anon., "Wissenschaftliche Weltauffassung," 299 and 310-15. Collaboration and interdisciplinarity have long been central topics in the digital humanities; see, for example, Anne Burdick et al., Digital_Humanities (Cambridge: The MIT Press, 2012), 49-51. 
self. ${ }^{12}$ The universal nature of these criticisms points to a deeper impasse between digital work and critical theories of culture and aesthetics, which, akin to Horkheimer and Adorno, uphold the mismatch of scientific rationality and empirical, data-driven research with the complexity of humanistic inquiry into topics such as art, philosophy, and religious thought. ${ }^{13}$ At the risk of reductionism, it is against this ongoing stalemate between the empirical and the metaphysical in the humanities that, so I argue here, Rosenzweig's concept of "Bewährung" stands best poised to intervene.

Reading the visualizations of Rosenzweig's archive through his concept of "Bewährung" responds to ongoing theoretical debates, started by Alan Liu, Johanna Drucker and Lauren Klein, to define critical, humanities-based practices for digital work and to create alternative histories of and epistemologies for data visualization. ${ }^{14}$ For instance, Klein's article "The Image of Absence" demonstrates that data visualization holds the potential to render visible "archival silences" and to illuminate these present absences, such as those of James Hem-

12 The "dark side" of the digital humanities refers to a 2013 MLA roundtable, contributions from which appeared in the special issue, "The Shadows of the Digital Humanities," in differences (2014) edited by Elizabeth Weed and Ellen Rooney; see also Wendy Hui Kyong Chun et al., "The Dark Side of the Digital Humanities," in Debates in the Digital Humanities 2016, ed. Matthew K. Gold and Lauren F. Klein (Minneapolis: University of Minnesota Press, 2016), 493-509. The term "digital positivism" has also become a symbol for the political and social dangers of big data, see Vincent Mosco, To the Cloud: Big Data in a Turbulent World (London: Routledge, 2014), chap. 5. The relationship between the digital humanities and neoliberalism has perhaps most forcefully been pointed out by Daniel Allington, Sarah Brouillette, and David Golumbia, "Neoliberal Tools (and Archives): A Political History of Digital Humanities," Los Angeles Review of Books, accessed January 17, 2017, https://lareviewofbooks.org/article/ne oliberal-tools-archives-political-history-digital-humanities/.

13 See, for instance, Tom Eyers, “The Perils of the 'Digital Humanities': New Positivisms and the Fate of Literary Theory,” Postmodern Culture 23, no. 2 (January 2013), http://www.pomoculture. org/2015/07/08/the-perils-of-the-digital-humanities-new-positivisms-and-the-fate-of-literary-theo ry/.

14 Theoretical debates have largely focused on, as Alan Liu put it, the place of cultural criticism in digital work; see "Where Is Cultural Criticism in the Digital Humanities?," in Debates in the Digital Humanities, ed. Matthew K. Gold (Minneapolis: University of Minnesota Press, 2012), 490 - 509. Drucker and Klein's work both propose ways that digital work addresses cultural-critical goals; see, for instance, Johanna Drucker, "Humanities Approaches to Graphical Display,” Digital Humanities Quarterly 5, no. 1 (2011), http://www.digitalhumanities.org/dhq/vol/5/1/ 000091/000091.html; Lauren F. Klein, "The Image of Absence: Archival Silence, Data Visualization, and James Hemings,” American Literature 85, no. 4 (2013): 661-88; Lauren F. Klein, "Feminist Data Visualization; Or, the Shape of History,” January 24, 2017, http://lklein.com/conference-papers/feminist-data-visualization-or-the-shape-of-history/. 
ings in Thomas Jefferson's papers. ${ }^{15}$ Building on such work, I argue that reading images of Rosenzweig's diasporic holdings through the conceptual framework of "Bewährung" draws our attention to the negative underside of each visualization, by reminding us of the not-yet-realized totality hinted at, but not achieved by every "positive" image. True to the prohibition of divine images in Judaism, Rosenzweig's concept of "Bewährung” thus poses a conceptual response to, in the words of the "Manifesto of Modernist Digital Humanities" (2014), the "chauvinist" impulse of positivism, which the logical positivists expressed perhaps best through their claim that "everything is accessible to man" through unified science, which "know[s] no unsolvable riddle."16 To be sure, Rosenzweig scholars stand to learn a lot in terms of positive knowledge from visualizing archival metadata-from a fuller picture of his intellectual networks to the need to investigate Rosenzweig's underrepresented interlocutors. But these visualizations also teach us that, as critical theory is wrong to dismiss the digital outright, the digital humanities also risk lapsing from criticality to the danger that Marcuse located in positivism the minute they view their method and results as Absolute.

Exploring the uses of library and archival metadata as well as the relevance of the ideas that these data describe, this article argues for the mutual dependence of the empirical-concrete and theoretical-transcendental dimensions of the digital humanities. The following three sections each examine a step in the evolution of the concept of "Bewährung" (representation, temporality, and epistemology) in Rosenzweig's thinking and show how they locate the productive moments of negativity in visualizations of the metadata from Rosenzweig's archival holdings in Germany and the United States. ${ }^{17}$ The digital humanities-and, in

15 Klein, "The Image of Absence," 665.

16 Alex Christie et al., "Manifesto of Modernist Digital Humanities," hcommons.org, November 14, 2014, http://dx.doi.org/10.17613/M6824T. Anon., "Wissenschaftliche Weltauffassung," 306. Similar utopian and, as criticized by Stanley Fish in The New York Times, "messianic" tendencies have characterized debates in and skepticism toward the digital humanities, Stanley Fish, "Mind Your P's and B's: The Digital Humanities and Interpretation," The New York Times, January 23, 2012, https://opinionator.blogs.nytimes.com/2012/01/23/mind-your-ps-and-bs-the-digi tal-humanities-and-interpretation/. For an overview of the link between digital work and utopianism, see Brian Greenspan, “Are Digital Humanists Utopian?," in Debates in the Digital Humanities 2016, ed. Matthew K. Gold and Lauren F. Klein (Minneapolis: University of Minnesota Press, 2016), 393-409.

17 The various holdings that make up Rosenzweig's diasporic archive reflect the fate of German Jews fleeing Nazi Germany. The major collections of Rosenzweig's papers and letters are held in the Rosenzweig Teilnachlass at the University of Kassel Library, the Papers of Franz Rosenzweig at the Leo Baeck Institute (New York), the Glatzer Collection and Archives at Vanderbilt University, and the Papers of Eugen Rosenstock at Dartmouth University. 
particular, library and archival data-have much to offer both Rosenzweig studies and Religious Studies, including broader and more efficient access to the archival record and the computational analysis of texts and metadata. At the same time, ideas usually considered the purview of Religious Studies, such as "Bewährung," will be essential if scholars, librarians, and archivists are to address not only the empirical but also the metaphysical forces at play in the digital humanities.

\section{Representation}

One could say that the central task of Rosenzweig's thought is to reposition the human as a thinking and existing being at the center of philosophical inquiry. In line with renewed interests in existentialism and esotericism in early-twentiethcentury Germany, his magnum opus, The Star of Redemption (1921), sought to rescue the individual from obscurity in Hegel's program of Idealism, while maintaining a relationship between human finitude and divine eternity. ${ }^{18}$ For Rosenzweig, this relationship is theological, where God, the Absolute, is truth; but, in moves that often seem well ahead of their time, The Star of Redemption claims that humans cannot grasp the Absolute as a singular act of thinking and, instead, "have only a share" of the "whole" truth (God) in Christianity and Judaism. ${ }^{19}$ As finite beings, we know truth in as much as it can be "be veri-fied, and just in the way in which it is generally denied: namely, by letting the 'whole' truth rest on itself and yet taking the share that we comply with for eternal truth." 20 This passage, to which I will return throughout this section, suggests that the concept of "Bewährung" establishes a link between the transient and the eternal, which is both active and representational to the extent that we

18 Peter Gordon has examined Rosenzweig's relationship to existentialism and other existentialist thinkers, such as Martin Heidegger, in Rosenzweig and Heidegger: Between Judaism and German Philosophy (Berkeley: University of California Press, 2003). Benjamin Pollock shows the lasting importance of the Absolute in Rosenzweig's philosophy, Benjamin Pollock, Franz Rosenzweig and the Systematic Task of Philosophy (Cambridge: Cambridge University Press, 2009). On the entwinement of aesthetics and mysticism in the early twentieth century, see the canonical work Martina Wagner-Egelhaaf, Mystik der Moderne: die visionäre Ästhetik der deutschen Literatur im 20. Jahrhundert (Stuttgart: J.B. Metzler, 1989).

19 See, for instance, Robert Gibbs, Correlations in Rosenzweig and Levinas (Princeton: Princeton University Press, 1992). Franz Rosenzweig, The Star of Redemption, trans. Barbara E. Galli (Madison, Wis: University of Wisconsin Press, 2005), 438-39. For the German, see Franz Rosenzweig, Der Stern der Erlösung, ed. Reinhold Mayer (Den Haag: Martinus Nijhoff, 1976).

20 Rosenzweig, The Star of Redemption, 416. 
"take" a finite portion of the truth in place of an unrealizable whole. There are limitations to Rosenzweig's conceptual language, which regrettably excludes non-Judeo-Christian religions. ${ }^{21}$ But the idea of "Bewährung” points to a salient problem recognizable in debates over the digital humanities, namely the ways in which empirical, data-driven research can work in the service of critical goals greater than itself, such as the project of knowledge or ethical action.

But how, exactly, does Rosenzweig envision "Bewährung” working in practice? One clue lies in its etymology. The verb "bewähren" derives from the Old High German "biwāren," which means "to make true, to validate," formed from the adjective "true” ("wahr”). ${ }^{22}$ "Bewährung” as validation implies making a proposition "true," which can be seen in its usage in criminal justice where to be "auf Bewährung” ("on probation") means to prove through your actions that you are trustworthy; similarly, "Bewährung” was the name the logical positivists gave the process by which theoretical statements are verified by empirical experimentation. ${ }^{23}$ In The Star of Redemption, the previous passage picks up on these meanings by using the passive without reintroducing an agent in order to emphasize the idea of process. But the text also reimagines "Bewährung" as satisfying two conditions, the first of which requires the here-and-now of my lived experience and worldly action to reflect "the eternal truth" postulated by religious belief. The second condition stipulates that humans recognize that finite beings can never experience "the 'whole' truth" and, hence, not make claims to possess the Absolute in full. For Rosenzweig, this meant that participation in the finite but recurring liturgical cycles upholds the "whole" truth, which gives meaning to my finite existence even as "the 'whole' truth rest[s]" outside of historical experience. The reciprocity of this relationship is what Rosenzweig hints at when he reverses truth as a process of verifying versus denying: rather than the experience of worldly transience precluding the existence of the eternal, human finitude dialectically implies the Absolute. At a historical moment when the Absolute of Hegel's Idealism threatened to erase the individual, "Bewährung” did not reject the Absolute tout court (as would positivism), but rather made the infinite depend on its substantiation in finite experience.

21 On this problem, see the contributions to Rosenzweig Jahrbuch 2, ed. Martin Brasser.

22 Friedrich Kluge and Elmar Seebold, Etymologisches Wörterbuch der deutschen Sprache, 24th ed. (Berlin: De Gruyter, 2002), 118.

23 To avoid the paradoxes associated with common use of the term "true" ("wahr"), Rudolf Carnap proposed the term "verification" as a way of deciding whether to accept or deny the validity of a scientific statement; for Carnap, "verification" occurred by testing statements against empirical observation and comparing them to other known statements. Rudolf Carnap, "Wahrheit und Bewährung,” Actes du Congrès International de Philosophie Scientifique 4 (1936): 18 and 23. 
What sets "Bewährung" apart from a simple mystical bridge between the human and eternity (and makes it relevant today) is the negativity of the mechanism of representation at work in the relationship that "Bewährung" posits between the finite and infinite. As Leora Batnitzky writes, representation takes on a special meaning for Rosenzweig, signifying not a mode of presentation, but rather the act of standing-in-for, in the sense of the German Vertreter and vertreten, 'which mean 'representative' and 'to represent' in a political and ethical sense." ${ }^{24}$ Representation plays a key role in the larger theological claim of The Star of Redemption, which is that Christian and Jewish liturgical practice "verifies" the truth of God by representing in finite experience (human work in the world) the eternity of redemption (the Kingdom of God). As finite (experiential) and eternal (circular), these yearly liturgical forms "represent the redeemed supra-world to knowledge," but, as Rosenzweig cautions, "knowledge only recognizes them; it does not see beyond them." ${ }^{25}$ Here we see the negativity of representation, a moment of ontological non-identity, in which one thing may stand in and act in place of another, but will never be it.

"Bewährung" allows for knowledge to be empirical and experiential, but this moment of non-identity sets limits to the epistemological claims of empiricism that avoid a false postulate of totality, as in positivism. "Verification [Bewährung] takes place in that which is most one's own, in the individual life" (e.g., participating in the liturgical cycles), The Star of Redemption claims, but where the "whole" truth cannot itself become the matter of human experience, it "can be seen [geschaut]. Not experienced: for this we have recognized, that the highest only falls to humans' share when it becomes part. But seen." ${ }^{26}$ Intimately tied to the topic of idolatry, this passage makes an important distinction: while humans never experience the Absolute, we "see" the Absolute as represented in the religious experience of liturgy. ${ }^{27}$ We can have representatives of the Absolute, but knowledge of the Absolute in any representative becomes false once we take a representation for that which it represents. Beyond its theological stakes, "Bewährung" opens up the possibility of a form of knowledge that is empirical and metaphysical at the same time, in which experience is a form of knowing that becomes knowledge only when set into a relationship with a claim to the Absolute that transcends the parameters of human finitude.

24 Leora Batnitzky, Idolatry and Representation: The Philosophy of Franz Rosenzweig Reconsidered (Princeton: Princeton University Press, 2000), 29.

25 Rosenzweig, The Star of Redemption, 312. [translation modified]

26 Rosenzweig, 417. [translation modified]

27 For more on Rosenzweig's thinking on idolatry, see Batnitzky, Idolatry and Representation, here, 12 . 
The representative relationship between the empirical and the metaphysical proposed by "Bewährung" broadens the epistemological horizons in which we can think about the so-called positive knowledge produced by digital work. My goal here, I remind readers, is not to build a strict analogy between "Bewährung" and the digital humanities - that the activities of a digital archivist, as important as they are, represent some kind of divine Absolute. Instead, consider a visualization of the correspondence networks from Rosenzweig's partial archive deposited at the University of Kassel, which I created from an archival finding aid and published in 2015. The image shows the interconnections of approximately one thousand letters sent primarily to and from Rosenzweig and his family (e.g., Edith Rosenzweig, Adele and Georg Rosenzweig) and intellectual interlocutors (his cousins, Hans and Rudolf Ehrenberg). As correspondences were an important site of intellectual exchange for Rosenzweig, visualizing these networks offers scholars of Rosenzweig insight into how he shaped interwar debates on translation theory (as in the letters between Ernst Simon and Siegfried Kracauer) and renders legible the presence in his archive of voices marginalized in his collected works and research into his thought (especially those of his female correspondents, such as Margarete Susman). ${ }^{28}$ The data from the Kassel archive and its visualization, which following sections expand with further and updated data from Rosenzweig holdings, presents to scholars an image (a representative, to use Rosenzweig's term) of the social structure of German Jewish personal and intellectual life surrounding Rosenzweig.

And yet, in terms of "Bewährung," this image as a "representative" contains and exhibits the negative dimension of representation. For instance, it flattens the temporality of hundreds of letters, which were exchanged over the course of century; it lacks the content of the letters; and it obscures the fact that the correspondences housed in Kassel are only a part of a complete archive of Rosenzweig's extant work. Beyond the structures of Rosenzweig's correspondence networks, the visualization offers such negative markers of the discontinuities in Rosenzweig's diasporic archive and the multi-generational attempt, which began during his lifetime, to preserve his philosophical and theological legacy. ${ }^{29}$

28 For instance, Ernst Simon and Edith Rosenzweig jointly published Rosenzweig's letters in 1935, six years after his death, as Franz Rosenzweig, Briefe, ed. Ernst Simon and Edith Rosenzweig (Berlin: Schocken Verlag, 1935).

29 One of the first moments of archival preservation was that of Rosenzweig's mother, Adele Rosenzweig, who, as researchers believe, made a 444-page typescript of her son's letters home during World War I (between August 1914 and July 1917). Wolfgang D. Herzfeld, "Einleitung," in Feldpostbriefe: Die Korrespondenz mit den Eltern, ed. Wolfgang D. Herzfeld (Freiburg: Verlag Karl Alber, 2013), 26-27. 


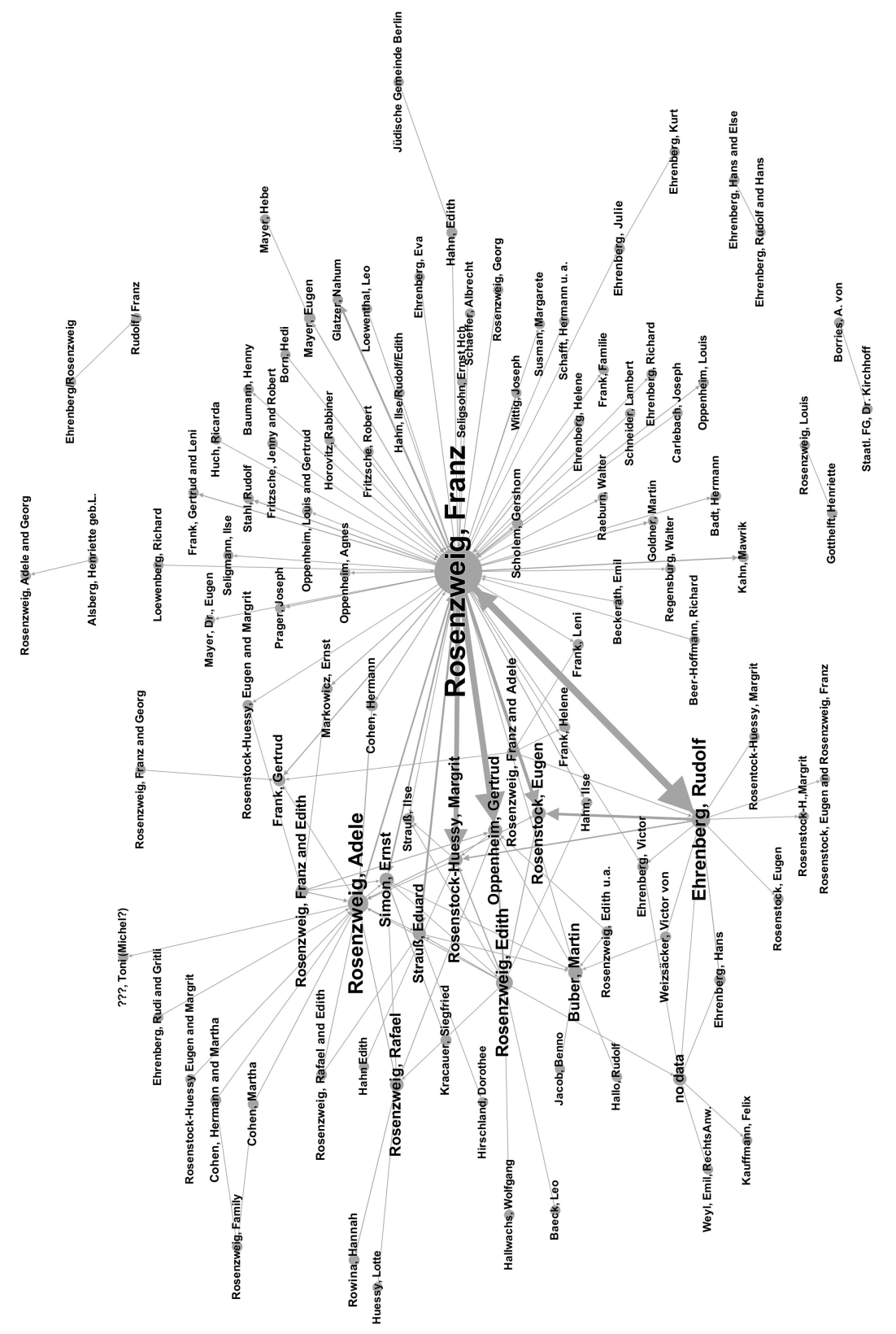

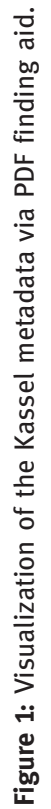


Developing strategies to interpret this negativity would expand on what Johanna Drucker has called for as a "visual epistemology" appropriate for humanities data. ${ }^{30}$ The visualization of Rosenzweig's archive thus not only produces positive knowledge to guide future research into Rosenzweig's work, but also, through its own limitations, hints at the theoretical-indeed, transcendental-preconditions that make knowledge of such an archive possible.

\section{Temporality}

The procedural nature of liturgy implies that one of the transcendental preconditions of the knowledge produced by "Bewährung" is temporality: our actions "verify" beliefs in our time and in the absolute course of time. Here, transcendental does not denote an ecstatic, esoteric, or, even, aesthetic mode by which humans can escape the limitations of finitude. Recall, instead, the distinction that Kant draws between "transcendent" and "transcendental": where transcendent objects exceed the possibilities of experience, "transcendental" signifies "our mode of cognition of objects insofar as this is to be possible a priori." 31 Transcendental principles are the conditions of possibility that allow us to have knowledge of objects. At points, the theoretical language of the transcendental, as with that of Rosenzweig's theology, seems at odds with the digital humanities and research enabled by archival and library data. ${ }^{32}$ Nonetheless, the political and ethical claims of the digital humanities, which have become central to its critical vocation, raise a number of salient questions about the conditions of knowledge and action in the digital age, such as how we are to understand and evaluate projects, like that of mapping Rosenzweig's correspondence networks, which exceed the limits of any individual researcher. ${ }^{33}$ As Rosenzweig's

30 Johanna Drucker, Graphesis: Visual Forms of Knowledge Production (Cambridge: Harvard University Press, 2014), 6.

31 Immanuel Kant, Critique of Pure Reason, trans. Paul Guyer and Allen W. Wood (Cambridge: Cambridge University Press, 1999), 149.

32 On this dynamic between digital humanities and theory, see the contributions to Journal of Digital Humanities, special issue on theory, especially: Natalia Cecire, "Introduction: Theory and the Virtues of Digital Humanities,” Journal of Digital Humanities 1, no. 1 (Winter 2011), http:// journalofdigitalhumanities.org/1-1/introduction-theory-and-the-virtues-of-digital-humanities-bynatalia-cecire/.

33 For instance, Roopika Risam has forcefully shown that digital humanities (and, in particular, what she explores as postcolonial digital humanities) can "remake the worlds instantiated in the digital cultural record through politically, ethically, and social justice-minded approaches," New 
response to a similar set of epistemological concerns, "Bewährung” suggests that a more complicated notion of temporality than simply that of an empty continuum, stretching from past to future, conditions the possibility of knowledge in the digital humanities.

One of Rosenzweig's most lucid explanations of the temporal dimension of "Bewährung” occurs in his brief correspondence with Siegfried Kracauer, a German Jewish journalist and later film theorist. Kracauer was deeply skeptical of the entwinement of philosophy and theology that runs throughout The Star of Redemption and Rosenzweig's thought. ${ }^{34}$ Rosenzweig's letter from March 1923 thus tries to convince Kracauer of the possibility that a system of belief can serve as a means of connecting the individual with the Absolute:

There is a way whereby an epoch, an -ism, or something similar can become absolute. But it eludes knowledge by proof or demonstration [...]; for its object is neither rational nor "irrational," but rather much simpler: not yet there at all. It's a question of a becoming-absolute, not of a being-absolute, a question of the one by the grace of the other; in a certain sense, a being-absolute by partial payments. It depends on whether the installments are paid on time-historically or, respectively, personally on time. Hence, logically (new-logically) speaking: it depends not on proof, but on verification [nicht auf den Beweis, sondern auf die Bewährung]..$^{35}$

This passage abounds with imagery and terminological distinctions, such as that between "proof" (Beweis) and "verification" (Bewährung), to which I will return. ${ }^{36}$ Its main point, however, is to describe the temporal frame in which "Bewährung" occurs: we produce knowledge in human time as an "epoch" (e.g., the postwar period) or a religious "-ism” (Judaism) participates in an unending (as described in The Star of Redemption) process of becoming an Absolute state of existence (the Kingdom of God). Amidst the skepticism and social changes of the early twentieth century, "Bewährung" upheld the possibility of knowledge, even if the "proof" of its absolute validity, in any logical or scientific sense of the word, stands outside of historical time.

Digital Worlds: Postcolonial Digital Humanities in Theory, Praxis, and Pedagogy (Evanston: Northwestern University Press, 2019), 4.

34 See Matthew Handelman, "The Forgotten Conversation. Five Letters from Franz Rosenzweig to Siegfried Kracauer, 1921-1923,” Scientia Poetica 15 (2011): 234-251.

35 Cited in Stephanie Baumann, “Drei Briefe - Franz Rosenzweig an Siegfried Kracauer," Zeitschrift für Religions- und Geistesgeschichte 63, no. 2 (2011): 174-75.

36 For instance, the word "installments" invokes Max Weber’s sociological use of "Bewährung” in his analyses of Protestantism, Max Weber, The Protestant Ethic and the "Spirit" of Capitalism and Other Writings, trans. Peter Baehr and Grodon C. Wells (New York: Penguin, 2002), 208. 
As the letter hints, the temporalities that condition the knowledge proper to "Bewährung" are really three different scales of time: the "personal" dimension of time, as in the work of an individual's lifetime, the "historical" dimension, as in the lifespan of epochs, and the Absolute dimension of time, as in the end of human time and beginning of the messianic age on earth. In contrast to a proof that flattens time by "demonstrating" the validity of a statement once and for all ("being-absolute"), "Bewährung" designates a form of knowledge that accrues over time as individuals ("personal") and groups ("historical”) "invest" in it over the absolute course of time. Here, we again see the productive negativity of the concept of "Bewährung," as knowledge that "becomes absolute" through time, but is a perpetual "not yet there" Absolute. One way to think about the first two temporalities is from the viewpoint of an individual engaged in such process-based knowledge, such as, to borrow an example from Friedrich Hölderlin, the poet who also must "bear the momentarily incomplete" in the process of writing. ${ }^{37}$ For Hölderlin, who was an important figure in Rosenzweig's work and intellectual biography, the creative mind remains in the moment to moment succession of writing the poem, while neither forgetting nor prematurely declaring the totality of its finished state. ${ }^{38}$ The concept of "Bewährung" adds a third temporal dimension: messianic time, which serves as a vanishing point that orients personal time away from the dangers of subjectivism (the view that my perspective is the Absolute) and relativism (that the Absolute is relative to a historical period). In contrast to knowledge that we "prove" to be eternally true, the process-based knowledge of "Bewährung" indicates that open-ended, longterm projects in the digital humanities may operate in distinct yet interrelated temporalities, such as those of individuals, groups, and a regulative totality akin to Rosenzweig's Absolute.

Reading on all three temporal levels gives form to the knowledge offered by the images of Rosenzweig's archive, but it also helps such digital work avoid the naivety of positivism. To be sure, there is an indirect resemblance between the actions of the believer in "Bewährung" and the critical work involved in creating

37 Friedrich Hölderlin, "Reflection," in Friedrich Hölderlin: Essays and Letters on Theory, trans. Thomas Pfau (Albany: SUNY Press, 1988), 46.

38 On Hölderlin's theory of poetry, see the work of Hannah Eldridge, whom I have to thank for the reference; Hannah Vandegrift Eldridge, Lyric Orientations: Hölderlin, Rilke, and the Poetics of Community (Ithaca: Cornell University Press, 2016), chap. 2. Hölderlin was one of the three suspected collaborators on the text "The Oldest System-Program of German Idealism," which Rosenzweig found in 1914 in the Prussian State Library and published in 1917, giving the text its title. On the role of German Idealism and the "Oldest System-Program of German Idealism," see Pollock, Franz Rosenzweig and the Systematic Task of Philosophy, chap. 1. 
and updating such a project. ${ }^{39}$ But consider the product of a second iteration of visualizing Rosenzweig's archive, which includes updated metadata from the University of Kassel as well as the metadata of Rosenzweig's correspondences deposited at Vanderbilt University's Divinity Library, the Leo Baeck Institute (New York), and the German Literary Archive (Deutsches Literaturarchiv, Marbach am Neckar). ${ }^{40}$ The entangled network surrounding the ego-node (Rosenzweig) indicates a deeper complexity to the structure of intellectual and personal exchange that informed Rosenzweig's thought, only the surface of which extant literature and archival publications scratch. Similar to Klein's "images of absence," we can think of these visualizations as positive images of erasure, which sketches the outlines of a German Jewish community disrupted by the rise of National Socialism and the exile of its members, Rosenzweig's family included. ${ }^{41}$

However, the network posited by these images raises the problem indicated in the Marcuse quote with which I began this article. For Marcuse, to take these data, the "matters of fact" as presented by such visualizations as a final authority, as in positivism, collapses the individual and historical levels of time with that of the messianic, presenting its image as final and fixed. It posits images

39 The iterative nature of digital humanities is a foundational trope, see Burdick et al., Digital_Humanities, 21.

40 These images include metadata from the partial archive at the University of Kassel; "Franz Rosenzweig,” n.d., https://www.uni-kassel.de/ub/landesbibliothek/sondersammlungen/nach laesse/rosenzweig. I have included the names of correspondents and number of letters at the Leo Baeck Institute in New York, but excluded those between Rosenzweig and his parents; "Collection: Franz Rosenzweig Collection,” n.d., https://archives.cjh.org//repositories/5/resources/ 11012. I have incorporated correspondent names and numbers of letters, such as Rosenzweig's letters to Kracauer, from the Deutsches Literaturarchiv and those at the Glatzer Collection at Vanderbilt University; "Franz Rosenzweig Papers | Collection Guides,” n.d., https://collections. library.vanderbilt.edu/repositories/2/archival_objects/217531. Due to the lack of available metadata at the time of writing, I have not included Rosenzweig's letters held at Dartmouth College and the National Library of Israel.

41 Rosenzweig's wife, Edith, and son, Rafael, immigrated to Palestine in 1938, while others, such as Kracauer and Rosenstock, emigrated to the United States and others, such as Leo Baeck, to England; on Kracauer's exile, see Johannes von Moltke, The Curious Humanist: Siegfried Kracauer in America (Berkeley: University of California Press, 2016). On Edith and Rafel's exile (and the fate of Rosenzweig's personal library), see Rafael Rosenzweig, "Augenblicke," in Vergegenwärtigungen des zerstörten jüdischen Erbes: Franz-Rosenzweig-Gastvorlesungen Kassel 1987-1998, ed. Wolfdietrich Schmied-Kowarzik (Kassel: Kassel University Press, 1997), 319-32; Norbert Waszek, Rosenzweigs Bibliothek: Der Katalog des Jahres 1939 mit einem Bericht über den derzeitigen Zustand in der tunesischen Nationalbibliothek (Freiburg: Verlag Karl Alber, 2017), 11. See also Julia Schneidawind, “A Diaspora of Books - Franz Rosenzweig's Library in Tunis,” Jewish Culture and History 22, no. 2 (2021): 140 - 53. 


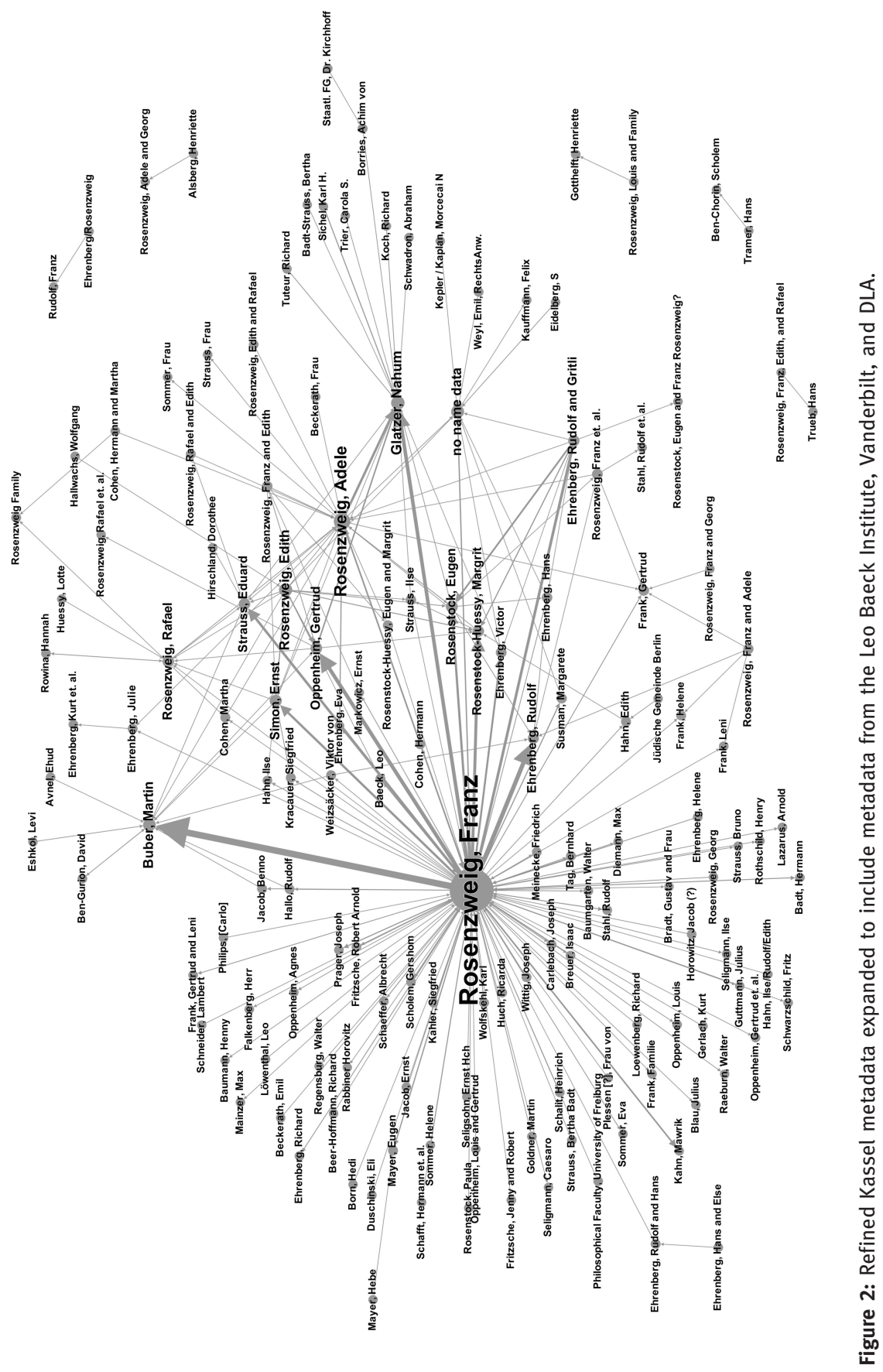




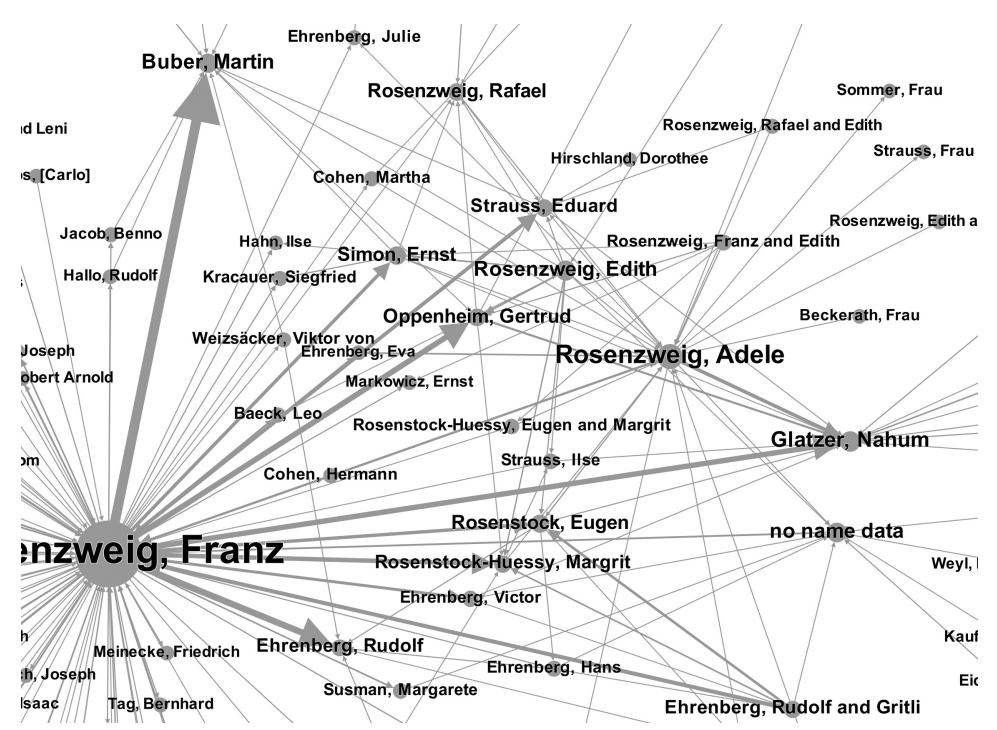

Figure 3: Close up of connections surrounding Rosenzweig.

of Rosenzweig's archive, without asking how the experience of exile and its interruption of the archival record shaped these images or imagining what they may have looked like without the disruptions of World War II. Considered in the light of "Bewährung," the contrast between initial and revised visualizations of Rosenzweig's archive shows something similar: while we improve on the breadth and accuracy of their representations and even our method of representing itself, there remains a moment of negativity in the temporal distance between our incomplete and finite work on Rosenzweig's legacy and the complete (messianic?) reconstruction of his archive.

Coming to interpretative terms with this negativity is a matter of locating and reading the discontinuities in the visualization and the moments at which the computational manipulation of metadata falters and fails. As mentioned in the first section, this image of Rosenzweig's archive flattens the temporality of the metadata and produces an overview of a social network at the cost of the granularity of data. But, at the same time, it also hints at the discontinuities and gaps in the archive as Rosenzweig's correspondence network prematurely terminates at the nodes of family, friends, and other interlocutors. For instance, the node of the conservative historian, Siegfried A. Kaehler, appears as a terminus, despite Kaehler's own correspondences with figures significant to Rose- 
nzweig, such as Margrit and Eugen Rosenstock. ${ }^{42}$ Moreover, we see a number of diodes discontinuous with the rest of the network, indicating the letters between Hans Tramer, the first chairman of the Leo Baeck Institute, and the historian Schalom Ben-Chorin in the Rosenzweig subset of the Nahum N. Glatzer Collection at Vanderbilt University, which represent the postwar preservation of German Jewish culture. As much as the visualizations provide positive images of erasure, a shadow of German Jewish intellectual life before war and in exile, their discontinuities and endpoints reveal not the "momentarily," but rather the perpetually "incomplete" state of any reconstruction of Rosenzweig's archive. These signs of non-totality are appeals to readers to take note, as many digital humanists put it, of the "future-oriented" nature of digital work and to put these particular images into dialog with the expansive temporal dimensions that they invoke: the work of generations of scholars in building Rosenzweig's archive and the negative moment of history itself. ${ }^{43}$ In this sense, to understand the knowledge produced by these images would mean formulating an epistemology that takes account of the open-ended temporal dimensions involved in working with library and archival data-an idea that Rosenzweig's letter to Kracauer hints at through its epistemological distinction between "proof" (Beweis) and "verification" (Bewährung).

\section{Epistemology}

The foundational epistemological problem addressed by "Bewährung" is the absence of a substantiation by which we recognize knowledge as valid, in as much as such substantiation lies beyond the parameters of finite experience. In mathematics and logic, the standard method of demonstrating the validity of a statement is "proof" (Beweis): to prove a claim, in mathematical debates of Rosenzweig's time, was to be able to determine its validity (or invalidity) through a finite number of logical steps. ${ }^{44}$ (In the 1930s, it was by working through similar

42 In "Nachlass Siegfried A. Kaehler," n.d., http://hans.sub.uni-goettingen.de/nachlaesse/ Kaehler_Siegfried_August.pdf.

43 See Matthew Kirschenbaum, "Digital Humanities As/Is a Tactical Term," in Debates in the Digital Humanities, ed. Matthew K. Gold (Minneapolis: University of Minnesota Press, 2012), 416; Bethany Nowviskie, "Reconstitute the World," Bethany Nowviskie (blog), June 12, 2018, http://nowviskie.org/2018/reconstitute-the-world/.

44 See Rudolf Eisler, Handwörterbuch der Philosophie, 2nd ed., ed. Richard Müller-Friedenfels (Berlin: Mittler, 1922), 98. On the question of the possibility of a proof's finitude, see George Dys- 
ideas that Alan Turing described the idea of a so-called Turing machine: a mathematical model of computation, which set the stage for digital computers. ${ }^{45}$ ) Proof requires that individuals, mathematicians and scientists, show that a statement, to use Rosenzweig's terms, "is Absolute" in the finitude of their existence or to provide empirical evidence that definitively upholds their claims. But what about forms of knowledge for which the evidence cannot be the matter of finite experience-such as the existence of God-or for which a substantiation reaches beyond the temporal limits of an individual's and generation's lifespan-such as social change that combats racism? Are we to demote them, as in positivism, from the ranks of knowledge? "Bewährung," which Rosenzweig calls "the true proof [der wahre Beweis]," proposes an answer to these questions by turning proof inside out: instead of objects needing to be proved, it makes knowledge depend on the objectivity of our actions. ${ }^{46}$ Mediating between scientific, mathematical, and religious forms of knowledge, "Bewährung” presents an epistemology that includes provable knowledge and knowledge which lacks proof, such as human activity, without totalizing the one or the other.

While the term started out as a link between believer and "the 'whole' truth" in The Star of Redemption, "Bewährung" signals what an epistemological paradigm shift, with relevance to the status of knowledge in the digital humanities, may ultimately look like. Rosenzweig's essay, "The New Thinking” (1925), explicitly calls "Bewährung" a "messianic theory of knowledge" (messianische Erkenntnistheorie), which is "messianic" in that it defers the substantiation of knowledge beyond finite, human experience. Accordingly:

truth ceases to be what "is" true and becomes that which [wants to be] verified as true. The concept of the verification of truth becomes the basic concept of this new epistemology, which takes the place of the old epistemology's non-contradiction theory and object theory, and introduces, instead of the old static concept of objectivity, a dynamic concept. The hopelessly static truths, like those of mathematics, which were made into the point of departure by the old epistemology, without ever getting beyond this point of departure, are to be conceived from this perspective as the-lower-limiting case, as rest is conceived as the limiting case of motion, while the higher and highest truths are only capable of being grasped as truths from this perspective, instead of having to be relabeled as fictions, postulates, and needs. From those most unimportant truths of the type "two times two is four," on which people easily agree, with no other expense than a little bit of brainpower-for the

on's accessible discussion in George Dyson, Turing's Cathedral: The Origins of the Digital Universe (New York: Vintage, 2012), 246-49.

45 See Dyson, Turing's Cathedral, 247-48.

46 Franz Rosenzweig, Understanding the Sick and the Healthy: A View of World, Man, and God, trans. Nahum Norbert Glatzer (Cambridge: Harvard University Press, 1999), 36. [translation modified] 
multiplication table a little less, for the theory of relativity a little more-the way leads over those truths, for which a person is willing to pay, over to those, which a person cannot verify in any other way than with the sacrifice of his life, and finally to those whose truth can be verified only by the commitment of the lives of all generations. ${ }^{47}$

This passage asks the reader to reconsider the relationship between objects and their ability to be knowledge. In the first line, the passage rejects the idea that "truth" (akin to the Absolute in the Kracauer letter) can be considered to be a property of an object (for example: "this sentence is true"). Instead, again drawing attention to human activity through the use of the passive, it claims that "truth" needs the action of individuals ("sacrifice" and "commitment") to make it true ("this statement wants to be verified by someone"). It is not that an object is true, but rather that I, as an acting individual, and my actions as objects in the world (e.g., partaking in liturgical cycles) make themselves true in relation to the Absolute. Amidst the rising hegemony of scientific rationality, "Bewährung" gave voice to an alternative, future-oriented epistemology that weighs knowledge according not to its eternal validity, but rather to the "commitments" that we make to it.

The concept of "Bewährung" in Rosenzweig's "messianic theory of knowledge" holds relevance for digital work in that it proposes a "dynamic" spectrum of knowledge production that ranges from science and mathematics to religion and ethical action, without rejecting the one or the other. By making human action the "objective" epistemological standard, the passage here redefines the "perspective" from which we view knowledge. On the one hand, we can think of the "static" knowledge of mathematics as epistemologically trivial-or, in Rosenzweig's words, "unimportant"-precisely because it can be proved to be irrefutable and eternal. ${ }^{48}$ On the other hand, the open-ended processes of experience, such as work dedicated to a group or community, become the "higher" case of knowledge, because, while they lack a demonstrable proof, people are nonetheless willing to "pay" or "sacrifice their lives" for them. For Rosenzweig, then, knowledge is empirical and "objective" to the extent that we, from individuals to all generations, live out this knowledge in the world, across individuals

47 Franz Rosenzweig, "The New Thinking," in Philosophical and Theological Writings, trans. Paul Franks and Michael Morgan (Indianapolis: Hackett, 2000), 135-36.

48 By trivial, I mean that Rosenzweig presents a view of mathematics that borders on the notion that mathematics is one big tautology: all mathematical knowledge unfolds logically and analytically (e. g., without any empirical input) out of itself, meaning that it is only a matter of logical steps that lead from the "multiplication tables" to the "theory of relativity." On the origins of this viewpoint, see Handelman, Mathematical Imagination, chap. 2. 
and generations. Beyond Rosenzweig's rhetoric, we see a final productive moment of negativity in "Bewährung" here: while few would risk their money (let alone lives) to wager that $2+2=4$, the deeper, protean dimension of knowledge lies in ideas to which people freely dedicate their lives despite lacking confirmation of their validity. In terms of process-based and open-ended knowledge in the digital humanities, "Bewährung” suggests a shift in emphasis from discussions over the novelty and eternal validity of digital work to an epistemic paradigm that values knowledge, such as that provided by the metadata of Rosenzweig's archive, both for what it does in the world and in the context of the larger ethical, political, and epistemological goals in which it works.

We see these dynamics in interactions between the efforts of librarians, archivists, and researchers and the metadata and visualizations of Rosenzweig's archive, both of which work within the framework of ongoing research into Rosenzweig's life and work and German Jewish cultural and intellectual history. Especially as libraries and archives make archival finding aids available online and increase access to their metadata and materials, these data present us with the horizon of Rosenzweig's material record, codetermining, as researchers adjust their research practices in the digital age, the direction of archival research. ${ }^{49}$ As researchers compile ever more complex data about Rosenzweig's archiveconnecting it to, for instance, metadata from Kracauer's and Susman's archives-these data and visualizations also reframe our picture of Rosenzweig's intellectual milieu and of German Jewish social life in general. ${ }^{50}$ With the increased number of data points, this network draws attention to the centrality of a few specific nodes as interconnections of both archival holdings and distinct social groups in prewar Germany. By consciously designing the data to reflect a more inclusive view of German Jewish intellectual history, the image also serves as the site in which researchers can call attention to and begin investigation into underrepresented figures, such as Margarete Susman. We see close-up that Susman served as a significant actor in this intellectual milieu, connecting figures close to the Frankfurt School (e.g., Kracauer and Bloch) with members of the Jewish cultural renewal movement (e.g., Rosenzweig and Buber). While Susman moved away from Frankfurt in 1921 (and to a place, Bad Säckingen, which lies

49 See Jonathan Hess's reflections on the changes that massive digitization brings to German Jewish Studies, in "Studying Print Culture in the Digital Age," The Leo Baeck Institute Yearbook 54 (2009): 33-36.

50 I take this constellation of thinkers as a central component of Weimar-era Jewish intellectual life in Germany; see my article "The Forgotten Conversation” and Harry T. Craver, Reluctant Skeptic: Siegfried Kracauer and the Crises of Weimar Culture (New York: Berghahn, 2017). Data for these archives can be found at "Kalliope Verbund," n.d., https://kalliope-verbund.info/. 
literally on the margins of Germany) to care for her ailing child, these images help Susman reclaim her centrality in the Weimar-era Jewish intellectual networks. ${ }^{51}$ These visualizations-importantly-help us create a more inclusive picture of German Jewish intellectual history. But, fixed into a positive image, they risk falling prey to the idea that improvements in technological modes of representation can overcome the processes of marginalization, oppression, and erasure of the past and, in the end, vanquish them from our modes of representation in the future.

As it defers the final substantiation of knowledge beyond finite experience, "Bewährung" reminds digital humanists that paying attention to the negativity that inheres in the production of knowledge provides a means to avoid such a methodological positivism. Part of this task lies, as digital humanists such as Roopika Risam and Miriam Posner explain, in reworking technologies so that they do not recapitulate colonial, patriarchal, and Eurocentric systems of knowledge and power. ${ }^{52}$ Another part, "Bewähung" suggests, lies in reading the limitations-the lack of context and the formality of the network-of visualizing Rosenzweig's archive as a marker of negativity in our methods, both historical and digital. This negativity-a trade-off between a view of social interconnections for content-abounds in these visualizations, if not the digital humanities as a whole, indicating the need for hybrid epistemologies that would read Rosenzweig's thought in terms of both context and structure. Such an epistemology would draw, in part, on the methods of intellectual history, as employed in this article: contextualizing ideas in their specific historical time and place, such as the role of mysticism and the infinite in modernity, and closely reading their development over time. At the same time, it would conceptualize intellectual discourse as a network of ideas that do not develop so much as they circulate (such as the infinite after World War I) and take on conceptual forms (such as "Bewährung") as they move and evolve between individuals..$^{33}$ As "Bewährung" mediates between mathematical and religious knowledge, such an epistemology

51 See Margarete Susman, Ich habe viele Leben gelebt (Stuttgart: Deutsche Verlags-Anstalt, 1964); Ingrid Belke, "Siegfried Kracauer: Geschichte einer Begegnung," in Grenzgänge zwischen Dichtung, Philosophie und Kulturkritik: Über Margarete Susman, ed. Anke Gilleir and Barbara Hahn (Göttingen: Wallstein, 2012), 35-61.

52 See Risam, New Digital Worlds, 17. Miriam Posner, "What's Next: The Radical, Unrealized Potential of Digital Humanities," in Debates in the Digital Humanities 2016, ed. Matthew K. Gold and Lauren F. Klein (Minneapolis: University of Minnesota Press, 2016), 35.

53 This idea resonates with Barbara Hahn's proposal of a "network of relations or perhaps a 'weave"' as a way to represent what remains legible of Jewish women writers' contribution to German modernity; see The Jewess Pallas Athena: This Too a Theory of Modernity, trans. James McFarland (Princeton: Princeton University Press, 2005), 13. 


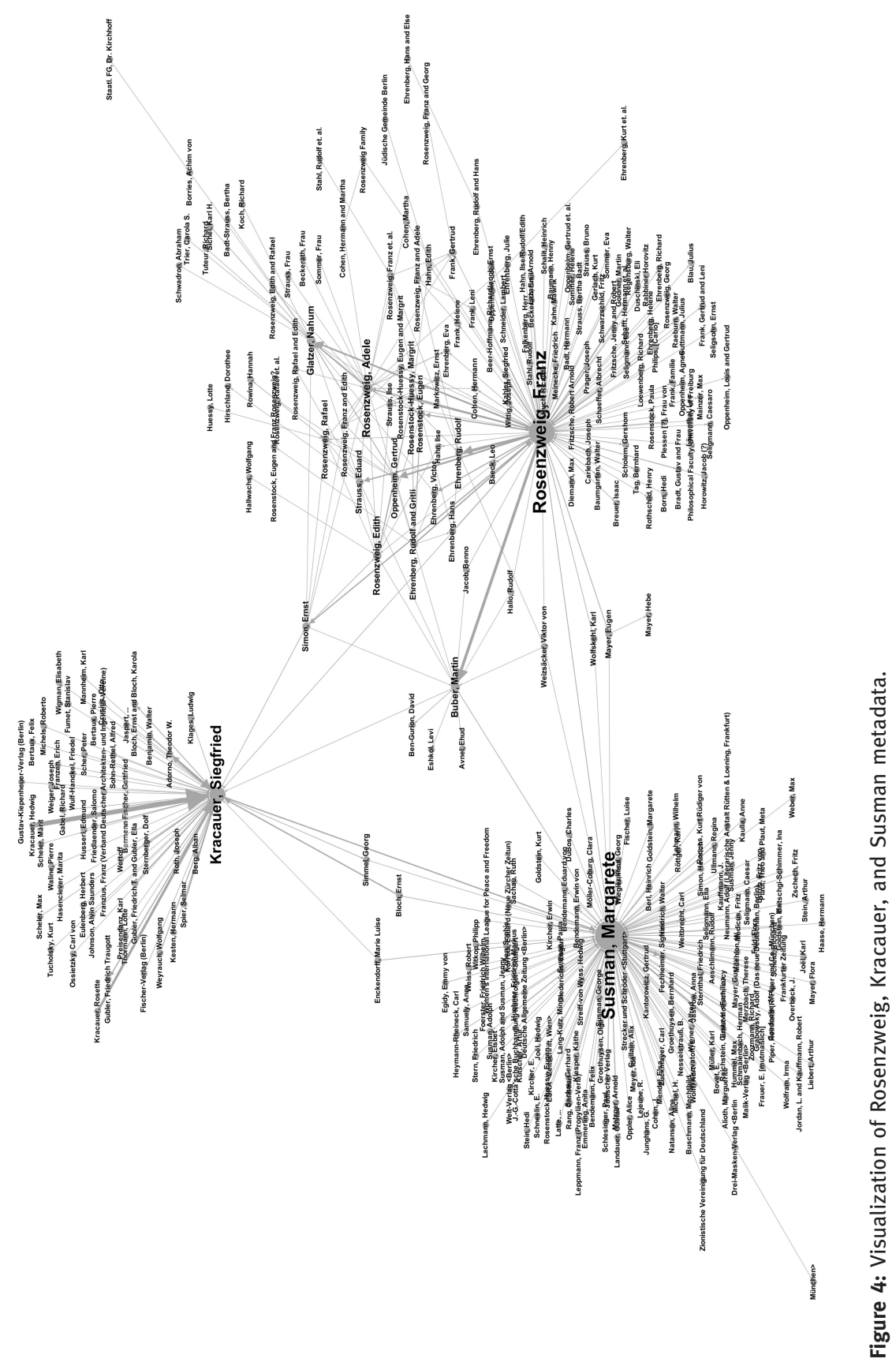




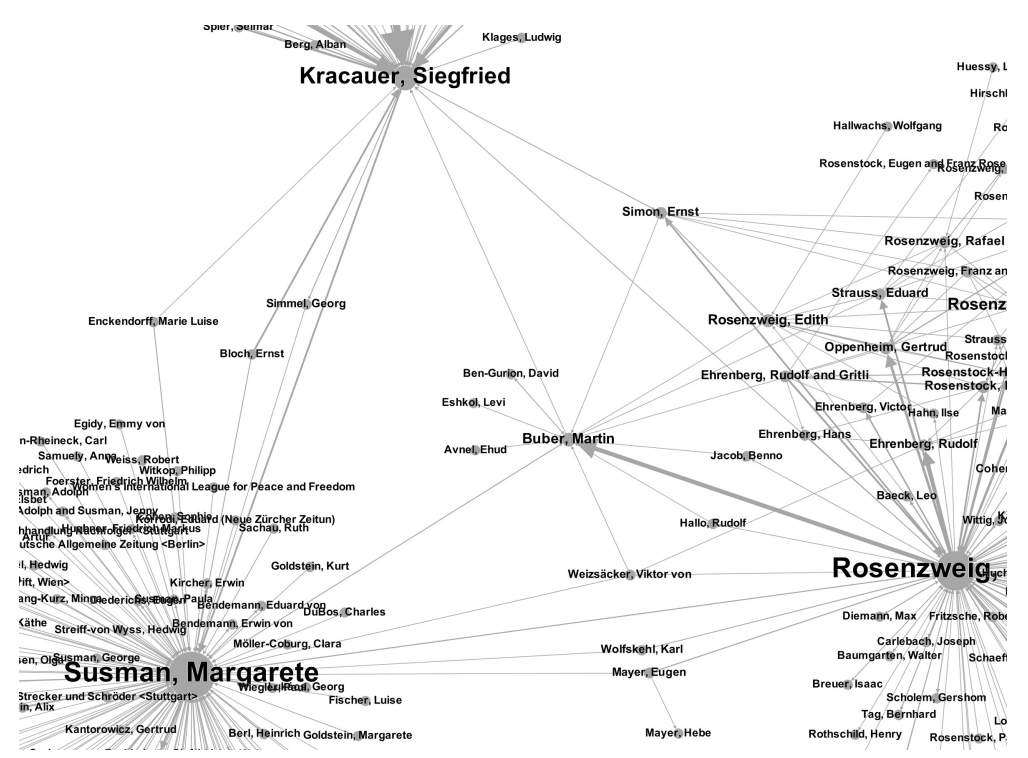

Figure 5: Close up of interconnections among Rosenzweig, Kracauer, and Susman.

would draw on both technical-scientific and close reading forms of knowledge, taking its own multi-disciplinarity as a representative of the not-yet-totality of our knowledge of both Rosenzweig and German Jewish intellectual life in the twentieth century.

\section{Conclusion: Rosenzweig in/and the Digital Age}

To return to the warning from Herbert Marcuse at the start of this article, the concept of “Bewährung” in Franz Rosenzweig's philosophy helps contemporary scholars come to terms with not only the potential but also the positivistic pitfalls of library and archival data and, more generally, the digital humanities. As seen in the visualizations of the correspondences that make up Rosenzweig's archive, library and archival data provides "positive” images of Rosenzweig's intellectual milieu and a partial visual reconstruction of the intellectual exchange that made up German Jewish life before National Socialism and characterized its continuation in exile. Along with drawing attention to underexplored intellectual voices in the network, the metadata of these archives and their visualization raise the possibility-and it would take the efforts of generations to achieve-of establishing an online, cross-institutional repository of Rosenzweig's archival holdings, including a database of extant archival materials, copies of relevant 
texts in the public domain, and even digitizations of these materials. ${ }^{54}$ This online archive would include materials discussed here, but also Rosenzweig's manuscripts and holdings from institutions with smaller Rosenzweig collections, which would make these resources accessible to students and scholars while allowing institutions to retain their holdings. The aim of this imagined archive taps into the progressive and emancipatory goals of digital work in the humanities: it promises to overcome the limits of the diaspora of archival materials and institutional politics, bringing back together, at least virtually, that which persecution, exile, and war broke apart.

In converse, Rosenzweig's concept of "Bewährung” and its associated "messianic theory of knowledge" provide strategies to avoid the political and ethical dangers of positivism involved with working with the library and archival data that make up Rosenzweig's archive-such as the idea of a unified Rosenzweig archive. Both the positivistic impulse to take the empirically given, the "data," as the totality of what is and the hope that scientific-technological methods may help compensate for the errors of the past are what make the visualizations of Rosenzweig's archive and the imagination of a unified Rosenzweig archive so seductive. They also underpin much of the writing on big data and business analytics on which the digital humanities often draws. Take, for instance, the idea that, as Kenneth Cukier and Viktor Mayer-Schönberger write, sampling in scientific experiments will come to an end as we reach an era in which sample sizes are " $n=$ all." 55 As the term " $n=$ all" parallels Rosenzweig's own investigation of the fate of "the All" in philosophy, the link that "Bewährung" forges between finitude and totality tempers positivism by reminding us of the irreducible metaphysical and theological dimensions of these claims-if not, as Clifford Anderson writes, the digital humanities as a whole. ${ }^{56}$ The suppressed metaphysics in

54 This iterative approach has been the model by which Rosenzweig's materials have appeared in print, from the first publication of his letters before World War II to their postwar expansion and republication in Franz Rosenzweig, Der Mensch und sein Werk: Briefe und Tagebücher, ed. Rachel Rosenzweig, Edith Rosenzweig-Scheinmann, and Bernhard Casper, 2 vols. (The Hauge: Martinus Nijhoff, 1979). Recent archival publications include Rosenzweig's wartime letters to his parents, in Franz Rosenzweig, Feldpostbriefe: Die Korrespondenz mit den Eltern (1914-1917), ed. Wolfgang D Herzfeld (Freiburg: K. Alber, 2013).

55 Viktor Mayer-Schönberger and Kenneth Cukier, Big Data: A Revolution That Will Transform How We Live, Work, and Think (Boston: Houghton Mifflin Harcourt, 2013), 26-31. See also Russell Walker, From Big Data to Big Profits: Success with Data and Analytics (Oxford: Oxford University Press, 2015), 17-19.

56 Clifford Anderson, "Digital Humanities and the Future of Theology," Cursor_ 1: Neuland (July 24, 2018), https://cursor.pubpub.org/pub/anderson-digitalhumanities-2018. 
the program of logical positivism was, after all, one of the criticisms that Horkheimer and Adorno made of the Vienna Circle, paving the way for the dialectic of enlightenment. ${ }^{57}$

Perhaps the solution is thus a theory of digital knowledge that would take account of the empirical and metaphysical elements of the digital, as it works in the service of ethics as well as rearranges the horizon of what the term ethics means. This is not to say that the future of digital humanities lies in a return to metaphysics. Rather, it means that the digital humanities stand to learn something from the practical and theoretical questions raised by theology and the concept of "Bewährung," in as much as all three are deeply concerned with questions of representation and temporality, epistemology and ethics. And, ultimately, it means that thinking through how theoretical claims shape our data and how data reshape our theoretical claims will allow us to come to terms with the metaphysical and, indeed, messianic element that has always been a part of any critical theory of digital knowledge.

57 This is the main point of Horkheimer's 1937 essay, “The Latest Attack on Metaphysics," in Critical Theory: Selected Essays, trans. Matthew J. O'Connell (New York: Continuum, 2002), 182-84. 
